\title{
Notes on the vocalizations of Marcapata Spinetail (Cranioleuca marcapatae)
}

Peter Boesman

In the following we briefly analyze and compare voice of the two races of Marcapata Spinetail (Cranioleuca marcapatae). We also try to quantify the extent of any vocal differences using the criteria proposed by Tobias et al. (2010), as a support for taxonomic review. We have made use of sound recordings available on-line from Xeno Canto (XC).

Song of both races is quite different:

weskei $(\mathrm{n}=7)$

Song is a short tinkling rattle of typically 7-9 descending overslurred notes, and usually ending with 13 more scratchy notes.

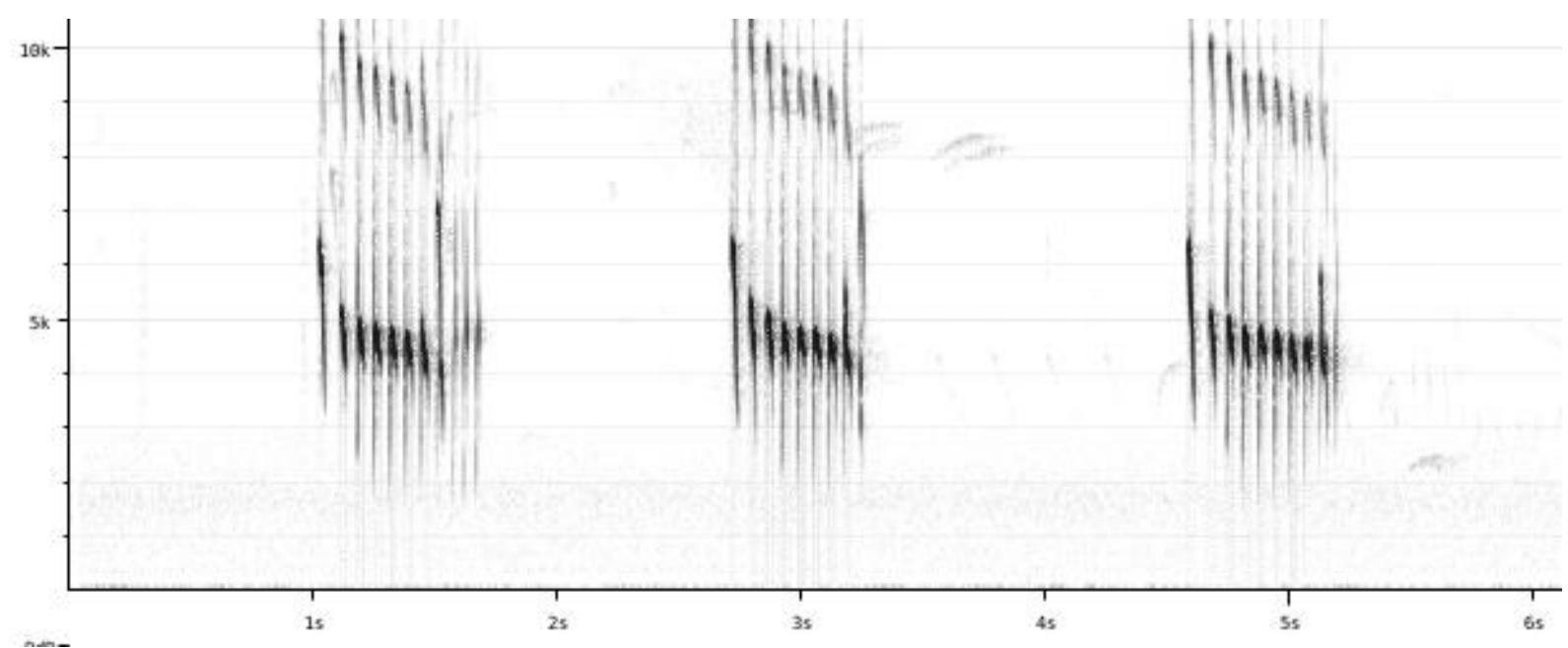

Measurements:

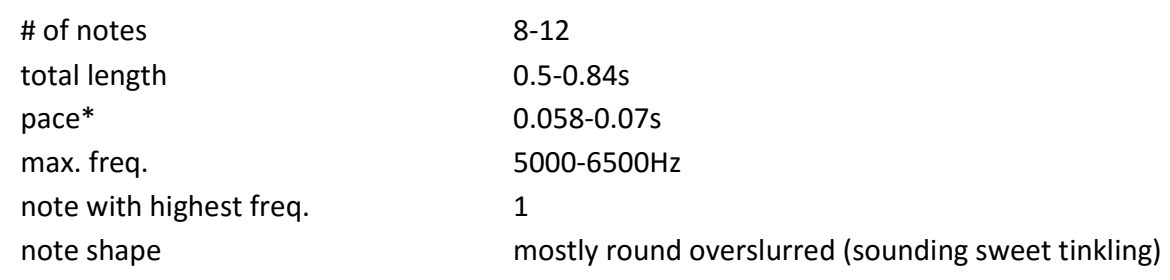

* Pace here expressed as period, average duration of note + pause 

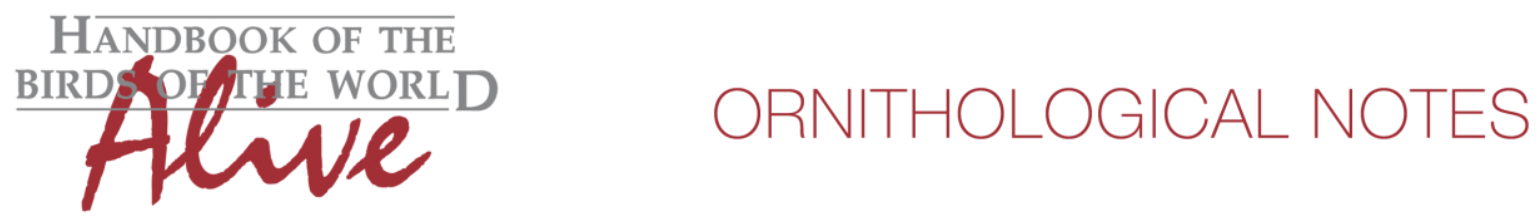

marcapatae $(\mathrm{n}=9)$

Song is much more variable than weskei, typically a loose series of rising/falling notes, often in longer sequences with alternating high-pitched and lower-pitched notes (presumably duets), and often ending with a short series of gravelly notes.

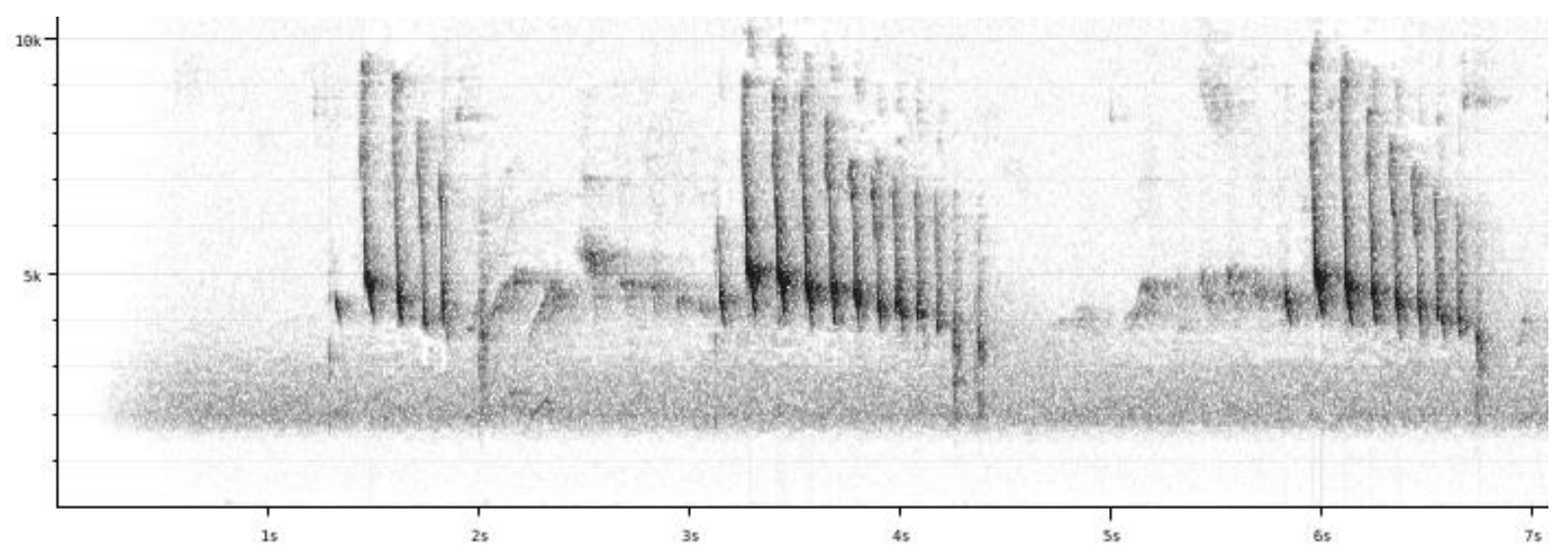

Measurements:

\# of notes

total length

pace

max. freq.

note with highest freq.

note shape
$10-30$

$1.0-3.4 \mathrm{~s}$

$0.11-0.14 \mathrm{~s}$

$7400-9400 \mathrm{~Hz}$

any place in the series, but basically never the first note

mostly spiky irregular shapes (sounding sharp and piercing)

\section{Conclusion}

Song of weskei differs from marcapatae by much more uniform delivery, shorter length (score=2), lower max. frequency (score=2), faster pace (score=2 or 3), descending song strophe (vs. rising and falling, score 2) and different note shape (score 1). This would lead to a total vocal score of 4 or 5 when applying Tobias criteria.

This note was finalized on 28th April 2015, using sound recordings available on-line at that moment. We would like to thank in particular the sound recordists who placed their recordings for this species on XC: Peter Boesman, Gunnar Engblom, David Geale, Andrew Spencer, Fabrice Schmitt and Herman Van Oosten. 


\section{References}

Tobias, J.A., Seddon, N., Spottiswoode, C.N., Pilgrim, J.D., Fishpool, L.D.C. \& Collar, N.J. (2010). Quantitative criteria for species delimitation. Ibis 152(4): 724-746.

\section{Recommended citation}

Boesman, P. (2016). Notes on the vocalizations of Marcapata Spinetail (Cranioleuca marcapatae). HBW Alive Ornithological Note 100. In: Handbook of the Birds of the World Alive. Lynx Edicions, Barcelona. (retrieved from http://www.hbw.com/node/932005 on 20 July 2016). 